\title{
1966: O ANO EM QUE FOUCAULT VENDEU COMO PÃEZINHOS
}

1966: THE YEAR THAT FOUCAULT HAS SOLD LIKE BREAD

Guilherme Almeida Ribeiro*

\section{RESUMO}

O artigo examina os efeitos da publicação de As palavras e as coisas em 1966, no que se refere às polêmicas em torno do momento francês do estruturalismo. Nesse sentido, são discutidos os diferentes diagnósticos proferidos por Foucault acerca do sentido difuso do estruturalismo no cenário filosófico francês do pós-guerra, especialmente quanto ao esgotamento das narrativas do humanismo marxista e fenomenológico. Trata-se também de apontar a singularidade da estratégia de Foucault quanto ao que ele compreendia serem as potências renovadoras do estruturalismo naquelas circunstâncias políticas e acadêmicas.

PALAVRAS-CHAVE: Michel Foucault (1926-1984). Estruturalismo. História da Filosofia. História Intelectual. Filosofia Francesa.

\begin{abstract}
The article examines the effects of the publication of The Order of Things, in 1966, in relation to the controversies surrounding the French structuralism time. In this sense, we discuss the different diagnoses delivered by Foucault about the diffuse sense of structuralism in the French philosophical scene from the postwar period, especially about the exhaustion of the narratives of marxist and phenomenological humanisms. It is also to point out the uniqueness of Foucault's strategy as to what he understood to be the renewing powers of structuralism in those political and academic circumstances.
\end{abstract}

KEY-WORDS: Michel Foucault (1926-1984). Structuralism. History of Philosophy. Intellectual History. French Philosophy.

\footnotetext{
* Doutor em Filosofia pela UFRJ; Professor de Filosofia do Instituto Superior de Educação do Rio de Janeiro (ISERJ). E-mail: guilhermealm@gmail.com
} 


\title{
INTRODUÇÃO
}

"Está em curso de formação uma cultura não dialética" (FOUCAULT, 1994a, p. 540), declarava Foucault em 1966 - ano em que As palavras e as coisas "vende como pãezinhos", conforme expressão estampada na edição de Le Nouvel Observateur de 10 de agosto daquele ano (ERIBON, 1990, p.159). O livro integrava a coleção "Biblioteca das Ciências Humanas" da Editora Gallimard, dirigida e editada pelo historiador Pierre Nora. Acerca da problemática nitidamente estruturalista da coleção, Pierre Nora comentará, anos depois, em uma entrevista concedida a François Dosse:

\begin{abstract}
Esboçavam-se pesquisas convergentes entre disciplinas separadas, em torno de uma problemática comum fundada no fato de que os homens falam para dizer coisas pelas quais não são forçosamente responsáveis, levam a cabo ações não forçosamente almejadas, são atravessados por determinações das quais não são conscientes e que os comandam [...] Por outro lado, um segundo movimento atravessava estas pesquisas, o conteúdo sociopolítico deste saber ao qual se atribuía um valor, no limite, subversivo. (DOSSE, 1993, p. 355).
\end{abstract}

Ao destacar o "conteúdo sociopolítico" e o "valor subversivo" da coleção, Pierre Nora toca em um aspecto decisivo do momento francês do estruturalismo. No que se refere a isto, caso tomemos As palavras e as coisas - melhor dizendo, seus efeitos - como elemento de análise, pode-se dizer que neste momento Foucault dava visibilidade a uma série de suspeitas sobre uma noção aparentemente tão inocente como a de "homem", a qual confrontava toda uma tradição humanista embutida na filosofia e nas ciências humanas:

Uma coisa em todo caso é certa: é que o homem não é o mais velho problema nem o mais constante que se tenha colocado ao saber humano (...) [seu aparecimento] foi o efeito de uma mudança nas disposições fundamentais do saber. O homem é uma invenção cuja recente data a arqueologia de nosso pensamento mostra facilmente. E talvez o fim próximo (FOUCAULT, 1987, p.403).

\section{FOUCAULT DIAGNOSTICA O ESTRUTURALISMO}

Se é verdade que várias constelações teóricas se afastarão em definitivo da dita 'galáxia estruturalista' em meados da década de sessenta, por outro lado também é possível afirmar que o momento francês do estruturalismo as interpelou decisivamente na década anterior. Diante desse giro em torno da influência da voga estrutural, consideramos como 
adoravelmente provocadora uma entrevista concedida por Foucault ao marxista italiano Duccio Trombadori em 1983 - vinte anos depois, portanto, do momento mais explosivo do estruturalismo na França —, na qual ele sugere que, à parte aqueles que aplicavam métodos estruturais na linguística e na mitologia comparativa, nenhum dos atores "que, por vontade ou à força, receberam a etiqueta de estruturalista sabiam exatamente do que se tratava" (FOUCAULT, 1994b, p. 195). Decerto, argumenta Foucault, teria havido aqueles que aplicavam o método estrutural em domínios muito precisos, como a linguística ou a mitologia comparada, e que sabiam bem o que era o estruturalismo. Mas desde que se ultrapassassem esses domínios de contornos bem estabelecidos, talvez fosse mais apropriado, segundo a análise de Foucault, tomar o momento francês do estruturalismo nos anos 60 contra o pano de fundo do formalismo europeu. Comenta, a respeito, Foucault:

\begin{abstract}
Não tenho certeza de que seria muito interessante tentar redefinir o que se chamou, nesta época, de estruturalismo [...]. O que me surpreende no que se chamou de movimento estruturalista na França e na Europa Ocidental por volta dos anos 60 é que ele era efetivamente um eco do esforço realizado em certos países do Leste, e em particular na Tchecoslováquia, para se libertar do dogmatismo marxista. (FOUCAULT, 1994b, p. 196).
\end{abstract}

Na avaliação de Foucault, ao lado dos debates acerca do estruturalismo na França, haveria outra questão de fundo: ao lado do barulho das polêmicas francesas e regionais, existiria ainda o murmúrio proveniente do incremento das pesquisas formalistas que se desenvolviam na URSS e na Europa central desde os anos 20 (Troubetskoy, Jakobson, Propp, Bakhtin), as quais, anteriores à revolução russa, foram duramente perseguidas pelo estalinismo. Conforme narra Foucault,

[...] a cultura, o pensamento e a arte formalistas no primeiro terço do século XX foram em geral associados a movimentos políticos, digamos críticos, de esquerda e mesmo, em certos casos, revolucionários, e o marxismo ocultou tudo isso: ele fez uma crítica violenta ao formalismo na arte e na teoria, que aparece claramente a partir da década de 30. Trinta anos depois [...] em certos países do Leste e em um país como a França, pessoas [começam] a abalar o dogmatismo marxista a partir de formas de análise, de tipos de análise que são obviamente inspirados pelo formalismo. (FOUCAULT, 1994b, p. 196).

Em outras palavras, para Foucault, muitas das contendas colocadas em torno do estruturalismo - notadamente no que tange às acusações marxistas de "tecnocracia do pensamento" e de "muralha burguesa" — poderiam ser também apreendidas como um 
contragolpe de conflitos que se colocavam na Europa oriental, sob o domínio da União Soviética. Foucault se refere a duas pequenas experiências pelas quais passou fora da França, que ilustrariam esse quadro. A primeira diz respeito à visita de um célebre filósofo francês muito provavelmente Sartre - , esperado com grande expectativa pelos tchecos, dado que se tratava não só da primeira visita de um intelectual não ligado oficialmente ao PC, como também por se dar em um período de grande agitação, próximo aos acontecimentos da primavera de Praga. Esse filósofo teria criticado severamente o estruturalismo, afirmando que este, ao tentar se opor às correntes ideológicas marxistas, se encontrava a serviço da burguesia e do capitalismo. Seguiu-se uma grande decepção por parte da plateia, porque o filósofo, assim, fornecia uma arma excepcional ao poder constituído pelos estalinistas e seus remanescentes na Tchecoslováquia, os quais, naquele momento, acabavam de ganhar um novo e inusitado aliado...

O outro relato diz respeito à experiência de Foucault na Hungria, em 1967. Convidado para um debate em uma universidade, propôs como tema da conferência o estruturalismo. Obteve como resposta de seu intérprete na ocasião: "há três coisas sobre as quais não podemos falar na universidade: o nazismo, o regime Horty e o estruturalismo" (FOUCAULT, 1994b, p. 89). Conta Foucault que, a partir dessas duas experiências, passou a compreender as discussões inflamadas acerca do estruturalismo como representando também a repercussão de lutas extremamente importantes que se desenrolavam na Europa oriental, em relação às quais a maior parte da comunidade acadêmica francesa estava cega.

Concomitante a isso, o que estaria em jogo na penetração do estruturalismo - agora falando em específico da França - , no que se refere à forte rejeição inicial encontrada por ele mesmo entre a comunidade marxista, seria o desafio posto por um discurso que se sustentaria em uma tripla negativa, a saber: não eram irracionalistas, não eram de direita e não estavam inseridos nem no interior do dogmatismo estalinista, nem do humanismo marxista e suas variantes. Nesse sentido, a constituição de uma larga e difusa rede de pesquisas, ramificadas em diversos campos e regiões do saber, legitimando-se sem maiores concessões ao materialismo dialético, foi uma questão importante na assimilação — e resistência — francesa à problemática estruturalista. 


\section{CONTROVÉRSIAS DO ANTI-HUMANISMO}

Voltando ao caso específico de Foucault, em especial às acusações e aos malentendidos que sofrera em torno do rebatido tema da 'morte do homem', associado ao estruturalismo, é essencial destacar o seu esforço e empreendimento teórico em As palavras e as coisas de, ao mergulhar radicalmente na historicidade, conjurar as quimeras das "origens" e de suas parceiras, as "finalidades" (FOUCAULT, 1987, p. 348). Decerto, todo um ajuste de contas com a hegemonia fenomenológica e marxista do pós-guerra atravessa a problemática tornada visível por As palavras e as coisas, como ficará explicitado nas diversas entrevistas concedidas por Foucault naquela ocasião, tal como a publicada por La Quinzaine Littéraire, em maio de 1966:

Há cerca de 15 anos, de uma maneira muito rápida, e sem que houvesse aparentemente razão, nós apercebemo-nos de que estávamos muito longe da geração precedente, da geração de Sartre, de Merleau-Ponty - a geração dos Temps Modernes que havia sido a lei para nosso pensamento e um modelo para nossa vida [...] O humanismo foi uma maneira de resolver em termos de moral, de valores, de reconciliação, problemas que não se podiam resolver de modo algum. Conhece a frase de Marx? A humanidade só formula problemas que pode resolver. Eu creio que se pode dizer: o humanismo finge resolver problemas que não se pode formular! Salvar o homem, redescobrir o homem no homem etc, é o fim de todas essas tentativas palavrosas, a um tempo teóricas e práticas, para reconciliar, por exemplo Marx e Teilhard de Chardin [...] a nossa tarefa atualmente é libertamo-nos definitivamente do humanismo, e nesse sentido o nosso trabalho é político, na medida em que todos os regimes do Leste e do Oeste fazem passar a sua mercadoria sob a bandeira do humanismo. (FOUCAULT, 1966, p. 14-15).

Também em outra entrevista, na revista Arts et Loisirs, publicada em junho do mesmo ano, Foucault endossa o diagnóstico:

\footnotetext{
Ora, não somente o humanismo não existe nas outras culturas, mas está provavelmente na nossa cultura na ordem da miragem. [...] Em As palavras e as coisas eu quis mostrar de quais peças e quais pedaços o homem foi composto no fim do século XVIII e início do XIX. Tentei caracterizar a modernidade dessa figura, e o que me pareceu importante era mostrar isso: não é tanto porque se teve um cuidado moral com o ser humano que se teve a ideia de conhecê-lo cientificamente, mas é pelo contrário porque se construiu o ser humano como objeto de um saber possível que em seguida desenvolveram-se todos os temas morais do humanismo contemporâneo, temas que são encontrados nos marxismos frouxos, em SaintExupéry e Camus, em Teilhard de Chardin, resumidamente, em todas essas figuras pálidas da nossa cultura. (FOUCAULT, 1994a, p. 540).
} 
No que diz respeito a Sartre, Foucault não deixa, na ocasião, de comentar acerca da Crítica da razão dialética, caracterizando-a como o "magnífico e patético esforço de um homem do século XIX para pensar o século XX" - Sartre seria "o último dos hegelianos":

\begin{abstract}
Grosso modo, pode-se dizer o seguinte: o humanismo, a antropologia e o pensamento dialético estão ligados. Aquilo que ignora o homem é a razão analítica contemporânea, que vimos nascer com Russel e que aparecerá em Lévi-Strauss e nos linguistas. Essa razão analítica é incompatível com o humanismo, enquanto que a dialética, ela, convoca acessoriamente o humanismo. Ela o convoca por razões diversas: porque ela é uma filosofia da história, porque ela é uma filosofia da prática humana, porque ela é uma filosofia da alienação e da reconciliação. Ela se nomeia por várias razões: porque é uma filosofia da história, porque é uma filosofia da prática humana, porque é uma filosofia da alienação e da reconciliação. Por todas essas razões e porque continua, no fundo, uma filosofia do retorno a si mesmo, a dialética promete em certa medida ao ser humano que ele se tornará um homem autêntico e verdadeiro. Ela promete o homem ao homem e, nessa medida, não é dissociável de uma moral humanista. Neste sentido, os grandes responsáveis do humanismo contemporâneo, são evidentemente Hegel e Marx. Ora, me parece que ao escrever a Critique de La Raison Dialectique de algum modo Sartre colocou um ponto final neste episódio da nossa cultura, tornando a fechar um parêntese que se inicia com Hegel. Ele fez tudo o que pôde para reintegrar a cultura contemporânea (quer dizer, as aquisições da psicanálise, da economia política, da história, da sociologia) à dialética. Mas é característico que ele não pudesse deixar à margem tudo aquilo que faz parte da cultura contemporânea: lógica, teoria da informação, linguística, formalismo. (FOUCAULT, 1994a, p. 540).
\end{abstract}

Os alvos contra os quais Foucault chegará, de certo modo, a empunhar alguma bandeira estruturalista — valorizando, em As palavras e as coisas, as 'contra-ciências' representadas pela psicanálise, pela linguística e pela etnologia — são os "humanismos frouxos", fossem eles de filiação marxista ou fenomenológica. Mas não somente. Como deixa entrever a referência à reconciliação 'Marx-Teilhard de Chardin', Foucault tratava também de registrar seu desprezo pelos apparatchiks (burocratas partidários) que proliferavam no PCF, os quais estariam sempre dispostos a um ecletismo que possibilitasse 'fazer passar a mercadoria'. Nesse sentido, convém lembrar que a trajetória do PCF nos anos sessenta é marcada por uma estratégia efetivada por seus intelectuais de maior prestígio, como Roger Garaudy: lançarem-se aos ecletismos doutrinários mais variados, com vistas à aproximação ao "pensamento burguês", acompanhando as alianças firmadas junto a antigos rivais políticos, como a SFIO e o regime gaullista. O lema passava a ser o do "humanismo socialista".

Em todas as intervenções acerca do 'estruturalismo' ao longo do dito "ano-estrutural" de 1966, além de remeter Sartre ao século XIX, Foucault opta por se situar firmemente ao lado de Lévi-Strauss, Dumézil, Lacan e Althusser — apreendidos como legítimos representantes da modernidade do século vinte. "O estruturalismo não é um método novo - é 
a consciência desperta e inquieta do saber moderno"; tal enunciado, recortado de As palavras e as coisas, irá se tornar um potente mote contra "a antropologização, [...], grande perigo interior do saber" (FOUCAULT, 1987, p. 365), o que justifica a apreciação futura de Eribon: naquele momento "parece evidente que Foucault se põe então em pé de igualdade na galáxia estruturalista” (ERIBON, 1990, p. 189).

Quanto a esse ponto, é importante assinalar que embora Foucault tenha insistido em nunca ter sido um estruturalista — insistência que foi também uma saudável resistência às tipologias redutoras e por vezes mortíferas —, irá assumir que o problema discutido pelo estruturalismo soava próximo de seus interesses; em especial, o problema do sujeito e de sua reformulação. Para Foucault, as investigações estruturalistas, muito diversas sob outros aspectos, convergiam em um único ponto: sua oposição filosófica à "afirmação teórica do primado do sujeito". Hegemônica na França desde que o cartesianismo alçara a condição de 'filosofia oficial', e que tendo servido de postulado fundamental para uma ampla gama de abordagens filosóficas dos anos 30 aos 50, em tal afirmação se inclui o 'existencialismo fenomenológico', o qual segundo Foucault seria “uma espécie de marxismo às voltas com o conceito de alienação" (FOUCAULT, 1994b, p.73).

No que tange especificamente ao marxismo, cabe inicialmente recordar que em $A s$ palavras e as coisas, Foucault o remetia à mesma 'episteme' novecentista de Ricardo, sem lhe conceder qualquer espécie de privilégio:

[...] no nível profundo do saber ocidental, o marxismo não introduziu nenhum corte real; alojou-se sem dificuldade [...] no interior de uma disposição epistemológica que o acolheu favoravelmente [...] e que ele não tinha [...] nem o propósito de perturbar nem sobretudo o poder de alterar, por pouco que fosse, pois que repousava inteiramente sobre ela. O marxismo está no pensamento do século XIX como peixe n'água: o que quer dizer que noutra parte qualquer deixa de respirar [...]. Seus debates podem agitar algumas ondas e desenhar sulcos na superfície: são tempestades num copo d'água. (FOUCAULT, 1987, p. 276).

Decerto dentre as ressonâncias políticas da 'problemática estruturalista', tal como a elas se referira Pierre Nora, certa oposição colocada frente ao marxismo ocupou um lugar de destaque. Dizemos certa oposição, pois que dirigida a certo marxismo, qual seja: aquele envolvido pelas brumas do humanismo teórico. É nesse sentido que Foucault irá posteriormente distinguir o marxismo althusseriano, em Arqueologia do saber, publicado em 1969. Tal como Foucault, ainda que por vias consideravelmente distintas, Althusser reconhecera como de extrema pertinência desembaraçar um dado campo - em seu caso, o 
marxismo - de constrangimentos hegeliano-fenomenológicos, os quais enfraqueceriam a potência contestadora do pensamento de Marx ao instalá-lo numa monótona reiteração: ora uma memória sempre em recuo — em busca da origem perdida — , ora uma promessa de reconciliação prometida - em um suposto apaziguamento colocado no fim-da-história. Evidentemente, não se trata aqui de assimilar Althusser à etiqueta estruturalista, à moda das monstruosidades da crítica. Mas sim de pôr em cena o que, em 1967, pretendia apontar François Furet (apud DOSSE, 1993, p. 394): se por um lado figuras como Henri Lefebvre continuariam a duramente remeter o êxito do estruturalismo ao estabelecimento da sociedade tecnocrática, outras, a exemplo de Louis Althusser, ao serem interpeladas pela voga estrutural, farão dela uma importante intercessora na abertura de novos caminhos ao marxismo francês — para além do ritmo das revelações dos gulags e das alianças "de ocasião" por parte do PCF em sua trajetória.

\section{CONSIDERAÇÕES FINAIS}

Não ignoramos que Foucault, apesar de seu inegável flerte com o dito 'estruturalismo', jamais se tenha considerado exatamente um estruturalista, na medida em que nunca reconheceu a existência necessária de estruturas formais ou reais, assim como sempre se manteve distante da lógica de identidade ou mesmo do cientificismo acirrado que por vezes a rubrica 'estruturalismo' incorporou. No entanto, cabe assinalar que, enquanto acontecimento, As palavras e as coisas funcionou como importante elemento do momento de difusão francesa da problemática estruturalista. É este modo de funcionamento que procuramos acompanhar e realçar ao longo deste trabalho.

A esta altura, é conveniente lembrar que desde História da loucura, publicada em 1961, a démarche foucaultiana já dava pistas claras de que não enveredaria por um modelo de história social que pretendesse se colocar sob o ponto de vista tradicional de uma pretensa restauração da coerência global do desenvolvimento ocidental. Soma-se a isto o privilégio à dimensão das formações discursivas, apreendidas com um acentuado grau de autonomia em relação às séries não discursivas, o qual fornece um outro fator de simpatia entre os objetivos de Foucault naquela ocasião e os princípios mais gerais reivindicados pelo estruturalismo à francesa a partir da década de 50. Em outras palavras, a afinidade com a recusa estruturalista da adoção irrefletida dos velhos modelos, às vezes implícitos, que procuravam integrar 
teoricamente qualquer mudança discursiva em um esquema meramente decalcado das contingências sociais, talvez seja algo de essencial a se ressaltar a fim de melhor se compreender a avaliação de Foucault quanto às possibilidades do estruturalismo. O estruturalismo, para Foucault, operava, naquelas circunstâncias do pós-guerra, como um apelo a se despertar de um sono dogmático - sono este, em larga medida, embalado pelos sonhos do humanismo, fosse ele de inclinação marxista ou fenomenológica, ambos com uma larga tradição de influência no cenário acadêmico francês. Quando rompemos com as quimeras das “origens" e de suas parceiras, as "finalidades" (FOUCAULT, 1987, p. 348), emergem descontinuidades e polimorfismos no campo dos saberes, os quais desmancham quaisquer possibilidades de reconstituição de uma dialética histórica à maneira antiga - nesse sentido será exato afirmar que "está em curso de formação uma cultura não dialética" (FOUCAULT, 1994a, p. 540).

As palavras e as coisas concretizaram o auge da aposta de Foucault nas promessas renovadoras do estruturalismo: esta é uma percepção que, embora verdadeira, merece ressalvas, conforme pudemos fazer notar. Não se pode, por exemplo, subestimar o privilégio dado por Foucault à categoria do impensado como ordenadora do a priori histórico, em cada etapa ou recorte dos sistemas de signos que é escandido por suas abordagens. Nesse sentido, Foucault, mesmo nos momentos de maior flerte com o estruturalismo, jamais se deixou levar por qualquer ranço de reivindicação por um positivismo semiológico ou histórico. A singularidade de seu projeto nos anos 60 é, inclusive, parte de uma revisão crítica das inclinações cientificistas do estruturalismo, convocando o olhar "estrutural" a uma abertura para as descontinuidades temporais e para as mudanças que regulam, ora mais, ora menos, os deslocamentos das práticas discursivas em um jogo que não cessa de ser jogado com relativa imprevisibilidade. Foucault não buscara enquadrar as múltiplas práticas discursivas em falsas continuidades que muito mal escondem o desejo de devolver ao homem o lugar de consciência soberana que restitui o sentido à história.

A guerra teórica anti-humanista de Foucault através de armas do espólio estruturalista, como sabemos, terá mais um capítulo em 1969, com Arqueologia do saber. Nela encontramos uma de suas mais belas provocações ao pensamento, bastante pertinente para aqueles que insistiam em perguntar ingenuamente se "afinal, Foucault é ou não é estruturalista?”:

Mais de uma pessoa, como eu sem dúvida, escreve para não ter mais rosto. Não me perguntem que sou nem me peçam que continue o mesmo: essa é uma moral de 
estado civil; ela rege nossos papéis. Que nos deixem livres quando a questão é escrever. (FOUCAULT, 2000, p. 23).

Podemos concluir que, às vésperas da década de 70, a fim de prosseguir em uma firme posição anti-humanista do ponto de vista teórico, Foucault já não mais se colocará ao lado dos que reivindicarão uma recuperação mais enfática do estruturalismo dos anos 60. Trata-se aí também de uma lição de desprendimento na relação a si próprio, com vistas a garantir aquela fidelidade necessariamente cruel dos que se movem em direção aos problemas, ao invés de exigir que estes se movam conforme as expectativas de solução já dadas.

\section{REFERÊNCIAS}

DOSSE, François. História do estruturalismo, vol.1. Tradução de Álvaro Cabral. São Paulo: Ensaio, 1993.

ERIBON, Didier. Michel Foucault, 1926-1984. Tradução de Hildegard Feist. São Paulo: Companhia das Letras, 1990.

FOUCAULT, Michel. Entretien avec Madeleine Chapsal. Le Quinzaine Littéraire, 5. p. 1415, Mai 16, 1966.

FOUCAULT, Michel. Structuralism and post-structuralism (interview with G. Raulet), Telos, Vol, XVI n255, p. 195-211, 1983.

FOUCAULT, Michel. As palavras e as coisas: uma arqueologia das ciências humanas. Tradução de Salma Tannus Muchail. São Paulo: Martins Fontes, 1987.

FOUCAULT, Michel. L'homme est-il mort? - Un entretien avec Michel Foucault. Dits et Écrits, vol.I. Paris: Gallimard, 1994a.

FOUCAULT, Michel. Entretien avec Michel Foucault, par Duccio Trombadori. Dits et Ècrits, vol IV. Paris: Gallimard, 1994b.

FOUCAULT, Michel. Arqueologia do Saber. Tradução de Luiz Felipe Baeta Neves. Rio de Janeiro: Forense Universitária, 2000. 